tory at the College of Physicians and Surgeons, Columbia University, succeeding Dr G. Draper, a pioneer in constitutional medicine. $\mathrm{He}$ has also held research appointments at the University of California, Berkeley, and, since 1951, at the University of Oregon Medical School.

Sheldon's earliest book (Psychology and the Promethean Will, 1936) and his latest one (Prometheus Revisited, 1975) are broad, provocative and provoking schemes for merging religious humanism with biologically grounded social psychiatry. Between these publications, he worked singlemindedly to propose and refine methods for describing individual human physical struoture: to develop a "biological identification tag". Best known are his primary components of endomorphy (roughly speaking, the sofitness and roundness of a physique), mesomorphy (heaviness of bone and muscle development), and ectomorphy (attenuation, "stretchedoutness"). By measuring the strength of each component in each individual and assigning a three-part index, the somatotype, Sheldon produced a tool which comes much closer to describing and encoding the great range of varia-

\section{Arthur C. Hardy}

Arthur C. Hardy, Professor of Physics at the Massachusetts Institute of Technology and inventor of the first recording spectrophotometer, died on 31 October at the age of 81 .

His specialist interests were in optics and photography, and after graduating at the University of California in 1917, he immediately became involved in photography in the first world war when he served in the American Expeditionary Force as a Commanding Officer in the Photographic Section of the U.S. Army. After the war he spent two years at the Kodak Research Laboratories before taking up an appointment in 1922 as Assistant Professor in Optics and Photography at MIT, where he spent the remainder of his professional life, becoming successively Associate Professor, full Professor and, in 1961, Emeritus Professor.

He played some part in the development of sound recording on film, while in 1930, in collaboration with Professor S. F. Brown, he developed an electric organ which was intended to reproduce the sound of any musical instrument. It is, though, with his famous recording spectrophotometer that his name will always be associated, since it is fair to say that this instrument revolutionised industrial colour measurement.

Until then, spectral transmission and reflection measurements were made with visual instruments and the observations were extremely laborious and were often impossible because of tions on the basic human body plan than was possible with older, pigeonholing typologies.

Over the years his methods moved through several revisions, toward objectivity and always seeking measures that maximise invariance, that evaluate physique not just as a current manifestation but as a lifelong trajectory. Along the way he has reported associations of somatotype with temperament, delinquency, and mental illness. His reports on physique, health, and longevity, followed in the surviving veterans of the Spanish-American war (1898), and on the later careers of 200 delinquent boys first studied 25 years ago, will be completed by his colleagues.

Sheldon's studies of some biological underpinnings of behaviour offered a much-needed counterbalance to a psychology one-sidedly emphasising learning and environment. Psychology regarded this offer doubtfully, though the term somatotyping found currency in labelling many sorts of physique appraisal methods, much as the term psychoanalysis was misapplied to all sorts of appraisal and treatment methods, and even "schools" of

shortage of light. The recording of a spectral reflection curve through the visible spectrum in the course of only a few minutes meant that it now became a commercial proposition for the colour industries to determine the key property of their products, namely the spectral absorption of a dye or pigment.

The instrument has really had a very remarkable history. It was developed in the 1920s at MIT and a fascinating account of how the design evolved was given by Professor Hardy in 1938 . (History of the Design of the Recording Spectrophotometer, J. opt. Soc. Am. 28, 360-364; 1938.)

A number of the MIT staff participated in the project and a major element in its success was the use of an optical attenuator, a train of polarising prisms, to balance the light reflected from the sample against the light reflected from a reference white. The photoelectric cell, which was in those days a rather uncertain device, could therefore be relegated to the role of a null detector. In more recent recording spectrophotometers, on the other hand, the measurement is usually obtained by comparing the photocurrents themselves using a ratiorecording potentiometer or similar device. Yet the Hardy instrument is still holding its own against all competitors and is still regarded by many users as the standard instrument for colour measurement.

It was produced commercially by the American General Electric Company somatotyping developed, like the schools of psychoanalysis (Sheldon found this comparison odious).

A keen observer, Sheldon was thoroughly convinced of the value and accuracy of his observations-an asset in a pioneer researcher, a problem to academic psychologists mistrustful of personal judgments. His irreverence for some of psychology's sacred cows, and his schoolboy's sense of mischief combined with a talent for finding just the right parallel in nature to point up a description of a human structure or action, have needled many a colleague. But Sheldon enjoyed his life. A sevendays-a-week worker, a diner at cafeterias because he could not stand the delays and pretentiousness of restaurants, an inveigher against the poisons in modern life, he was also wholehearted in his appreciation of an idea, a friend, a sparrow on his windowsill, an old coin. (Numismatists know him as the author of the standard work classifying early American cents.) His work cleared and broadened one roadway into the study of human biology and behaviour that had been an overgrown trail.

Richard N. Walker

as the G.E. Spectrophotometer, but it might have had an early rival from Westinghouse, since in $1930 \mathrm{I}$ was involved, as a research engineer with Westinghouse in Pittsburgh, in discussions about the production of a competitor. These were not, however, followed up. It is now manufactured by the Diano Corporation as the Diano-Hardy Spectrophotometer and, naturally enough, includes a number of modifications and accessories although the basic design is still the same after nearly 50 years.

A further contribution which Professor Hardy made to colour measurement was the publication in 1936 of the Handbook of Colorimetry, prepared under his direction by a team drawn from the staff of MIT. This was the first book on colorimetry to appear following the establishment, by the Commission Internationale de L'Eclairage, of the 1931 system of colour specification based on tables defining the colour-matching characteristics of a standard observer. The many charts and tables in the Handbook provided an excellent introduction to the CIE system and undoubtedly speeded up the use of the system for colour standardisation and as a tool in the colour industries.

Professor Hardy received a number of honours, including the Frederick Ives Medal of the Optical Society of America. $\mathrm{He}$ also served as President of the Society from 1935 to 1937 and as Secretary from 1940 to 1957.

W. D. Wright 